\title{
ASSESSMENT OF TWO MATERIALS IN PULPOTOMIZED IMMATURE PERMANENT MOLARS
}

\author{
Gihan Abuelniel" and Nihal Kabel**
}

\begin{abstract}
Introduction: There is insufficient evidence on the outcome of pulpotomy in carious exposed young permanent molars with the newer biomaterials. This study aimed to compare the outcomes of mineral trioxide aggregate (MTA) and Biodentine as pulpotomy materials in cariously exposed vital immature mandibular first permanent molars.

Methods: Sixty immature first mandibular permanent molars, with carious exposure were randomly assigned to MTA or Biodentine group in split-mouth design. After the amputation of the coronal pulp, the pulp stumps were covered with one of the study materials and coronal restorations placed. Blinded clinical and radiographic evaluations were performed at baseline, 6, 12 and 18 month and comparisons both between and within the two groups were made.

Results: A high success was observed in both groups for all outcome measures for clinical success, with no significant difference between the two groups. The mean survival time for Biodentine and MTA groups was (17.8 and 18 months) with the 95\% Confidence Interval (17.4 $18.2)$ and (18.0 - 18.0) months respectively. Similarly, there were no significant differences between Biodentine and MTA groups for radiographic success $(\mathrm{P}<0.001)$ with an increase in root length and increasing apical closure observed in both groups.
\end{abstract}

Conclusions: Both materials were equally effective in the treatment of cariously exposed vital immature mandibular first permanent molars.

\section{INTRODUCTION}

There is an ongoing debate on the use of vital pulp therapy in cariously-exposed pulps in immature permanent molars in children, with some authors recommending that this technique be considered for immature teeth ${ }^{(1)}$.
Carious exposures in young permanent molars may cause irreversible damage to the pulp tissue, arresting root development ${ }^{(2)}$. The main objective of treatment is to maintain pulp vitality for continuation of root development and apical closure, often referred to as apexogenesis in the literature ${ }^{(3)}$.

*Associate Professor of Paediatric Dentistry, Cairo University.

**Associate Professor of Paediatric Dentistry, Misr University for Sciences and Technology. 
Vital pulp therapies should provide a biologically conducive environment for the pulp tissue to heal and prevent future bacterial contamination by using an appropriate medicament followed by a sealed restoration of the coronal portion. Any material directly applied to the pulp should be biocompatible, ensure a biologic seal and induce hard tissue formation $^{(4)}$.

Calcium hydroxide $(\mathrm{CH})$, was perhaps the most commonly used material for vital pulp therapy for many decades ${ }^{(5)}$, but fell out of favour due to its many unintended side effects such as the existence of tunnel defects in induced dentinal bridges, poor adherence to dentine, and lack of long-term seal, amongst others. In the new era of regenerative endodontics, mineral trioxide aggregate (MTA), is considered as a gold standard, providing a long-term seal, acceptable biocompatibility ${ }^{(6)}$, and dentinal bridge formation as reported by various animal and human studies ${ }^{(7)}$.

MTA consists of tricalcium silicate, tricalcium aluminate, tricalcium oxide and silicate oxide as fine hydrophilic particles that set in the presence of moisture. It is widely considered as a remarkably biocompatible material with various clinical applications that include surgical and non-surgical applications such as pulp capping, furcation and perforation repairs, apexification and root end fillings ${ }^{(8)}$.

Biodentine, a relatively new bioactive calcium silicate-based cement was launched as a 'dentin substitute'. It has been reported that it penetrates through opened dentinal tubules to crystallize, interlocking with dentin to enhance the mechanical properties. Biodentine has been developed using MTA based cement technology with reportedly improved physical qualities and handling, and has wide range of applications in endodontic repair and pulp capping ${ }^{(9)}$.

Carious exposed young permanent molars pose a dilemma for clinicians as their extraction at an early age can compromise the occlusion rendering the child with further orthodontic needs. Endodontic management such as pulp extirpation and root obturation is severely compromised due to an incomplete root development. The availability of newer biocompatible materials opens up the possibility of removing the inflamed part of the pulpal tissue and facilitating the healing of the remaining pulp through the application of such a material followed by a good coronal seal. This would allow further root development, and even if these teeth ultimately became non-vital, their endodontic management would be simpler and would have better long-term outcome. Therefore, the objective of this prospective randomized clinical trial was to compare the clinical / radiographic outcomes of MTA and Biodentine used as pulpotomy biomaterials for the treatment of vital immature mandibular permanent first molars with carious pulp exposure in children.

\section{MATERIALS AND METHODS}

This study was approved by the ethics committee (number 19119) Cairo University and registered on clinicaltrial.gov (NCT03838094). Participants were healthy children who sought treatment in the Paediatric Dentistry. Parents were given information regarding the study and informed consent obtained. Selection and recruitment extended from February to September 2016. The inclusion and exclusion criteria were:

\section{Inclusion criteria}

- Children with bilateral asymptomatic symptomatic, vital immature mandibular first permanent molars, with clinical carious exposure of the pulp and presence of bleeding upon exposure.

- No history of spontaneous pain.

- Age range from 7-8 years.

- Absence of sinus tract, soft tissue swelling. 


\section{Exclusion criteria}

- History of spontaneous/ lingering pain, or pain that had woken the child at night.

- Non-restorable molars.

- Excessive mobility (more than $1 \mathrm{~mm}$ horizontally).

- Radiographic evidence of peri- and / or interradicular lesions, internal / external root resorption, pulp canal calcifications.

\section{Sample size calculation}

The study was a superiority 2 arm split mouth trial with a 1:1 allocation ratio. Sample size was calculated based upon the results of Alqaderi et al ${ }^{(10)}$ who reported clinical success rate (primary outcome) for MTA $=90 \%$. Since no clinical trials were found reporting the success rate of Biodentine in immature permanent teeth in paediatric patients at the time of participants enrolment, the success rate was assumed to be $55 \%$ according to expert opinion. Using alpha level $=0.05$ and $\beta$ level $=$ 0.20 ( $80 \%$ Power); the minimum estimated sample size was calculated to be 25 teeth per group. To compensate for a drop-out rate of $20 \%$, this was increased to a minimum of 30 teeth per group with a total of 60 teeth available for treatment. Sample size calculation was performed using IBM $^{\circledR}$ SPSS $^{\circledR}$ Sample Power ${ }^{\circledR}$ Release 3.0.1.

\section{Allocation and Allocation concealment}

Access cavity prepared molars were assigned into MTA or Biodentine group using simple randomization $1: 1$ by computer-generated sequence software (random.org). Allocation concealment was performed by the department secretary who obtained the random allocation list and informed the operator about the sequence just before placing the pulpotomy agent. Sequence generation and patient assignment was done by different investigators.

\section{Randomisation and Blinding}

Once the children who fulfilled the inclusion criteria were identified and consented, their molars were assigned randomly to the two groups in split mouth design. The MTA group was considered the control group while the Biodentine was the test group. The study included a total of thirty patients randomly assigned to each group with all children/ parents blinded to the treatment group they would be randomised to. The operator who performed all the clinical procedures took no further part in the assessment of outcomes, which were assessed by second blinded clinician, who performed the clinical assessments according to pre-defined criteria. All radiographic evaluations were performed by a blinded radiologist.

\section{Digital Radiographic Examination}

Patients who were clinically eligible for the study went through screening pre-operative digital periapical radiographic examination to assess the degree of root development and any dental infections or anomalies that could interfere with the planned treatment.

Digital periapical radiographs were taken using the SOREDEX (SOREDEX Nahkelantie 160, F104301 Tuusula, Finland) dental X-ray machine set at $70 \mathrm{kVp}, 8 \mathrm{~mA}$ and $0.08-0.04$ second. The digital radiographs were captured with the standardised periapical parallel technique using 16-inch position indicating device, Rinn XCP holder (XCP, RINN, United Kingdom) and PSP plate size 1 or 2. After the radiographs were taken, the PSP plate was scanned using the SOREDEX DIGORA Optimal digital intraoral scanner. The software Digora for windows 2.5 Rev 1 Soredex was used for image analysis.

\section{Vital Pulp Therapy}

One paediatric dentist performed all the pulpotomies. Local anaesthesia was administrated followed by rubber dam isolation. Caries was 
removed, and the resultant cavity was inspected for pulpal exposure. The molar and rubber dam were disinfected prior to entering the pulp cavity ${ }^{(11)}$. The pulp chamber was deroofed by a fissure diamond bur (Diatech, Heerbrug, Switzerland) and high-speed handpiece with coolant. The pulps were amputated to the orifice level of the root canals using a long-shank diamond round bur. Haemostasis was achieved by gentle placement of a saline-moistened cotton pellet over amputated pulps for 5 mins ${ }^{(12)}$.

\section{In control group}

Fast-setting mineral trioxide aggregate ENDOCEM MTA (Maruchi, Wonju-si, Korea) was used according to the manufacturer's instructions (13). A 3-mm-thick layer of MTA was placed over the amputated pulps and was gently adapted to the dentinal walls using a wet cotton pellet. A selfcure glass ionomer (GC; GC Corporation, Tokyo, Japan) was placed over the pulpotomy agent before final restoration of composite resin (ClearfilTM, Kuraray, New York, USA) was done, using a matrix band wherever required.

\section{Biodentine group}

Biodentine TM (Septodont Ltd., Saint Maur des Fausse's, France) was mixed according to the manufacturer's instructions ${ }^{(14)}$, and placed on the radicular pulp in a layer $3 \mathrm{~mm}$ thick, after which the molars received the final restoration.

\section{Immediate post -operative Radiograph (base line)}

After vital pulp therapy (pulpotomy), immediate post-operative digital periapical radiograph was taken to assess the quality of the clinical procedure and as a baseline. Demirjians et al ${ }^{(15)}$ teeth maturity scores were used to assess the base line stage of root formation.

The maturity scores used during the radiographic assessment of root development were described as:

F: a. The calcified region of the bifurcation has developed further down from its semi-lunar stage to give the roots a more definite and distinct outline with funnel shaped endings.

b. The root length is equal to or greater than the crown height.

G: The walls of the root canal are parallel and its apical end is still partially open (distal root in molars)

H: a. The apical end of the root canal is completely closed (distal root in molars).

b. The periodontal membrane has a uniform width around the root and the apex.

\section{Follow up:}

Clinical and radiographic follow-ups were carried out at intervals 6,12 and 18 months. A blinded second paediatric dentist performed clinical examinations according to criteria of clinical success, and a blinded oral radiologist performed radiographic examinations.

The flow of the patients in the study is summarised in Figure 1.

\section{Clinical criteria of success:}

The treatment was clinically considered a success, if the molars were functional with no signs/ symptoms of pulp and peri-radicular inflammation /infection as assessed by:

- Absence of pain related to the treated molars, including patient reported pain or sensitivity to percussion/palpation.

- No evidence of swelling of supporting soft tissue or presence of a sinus tract.

- Absence of excessive mobility.

\section{Final Digital Radiographic image analysis and radiographic criteria of success}

From the final digital image, the final teeth maturity scores for root development were recorded. Nosrat et al ${ }^{(12)}$ radiographic criteria for treatment success were applied with some modification to judge the treatment outcome: 


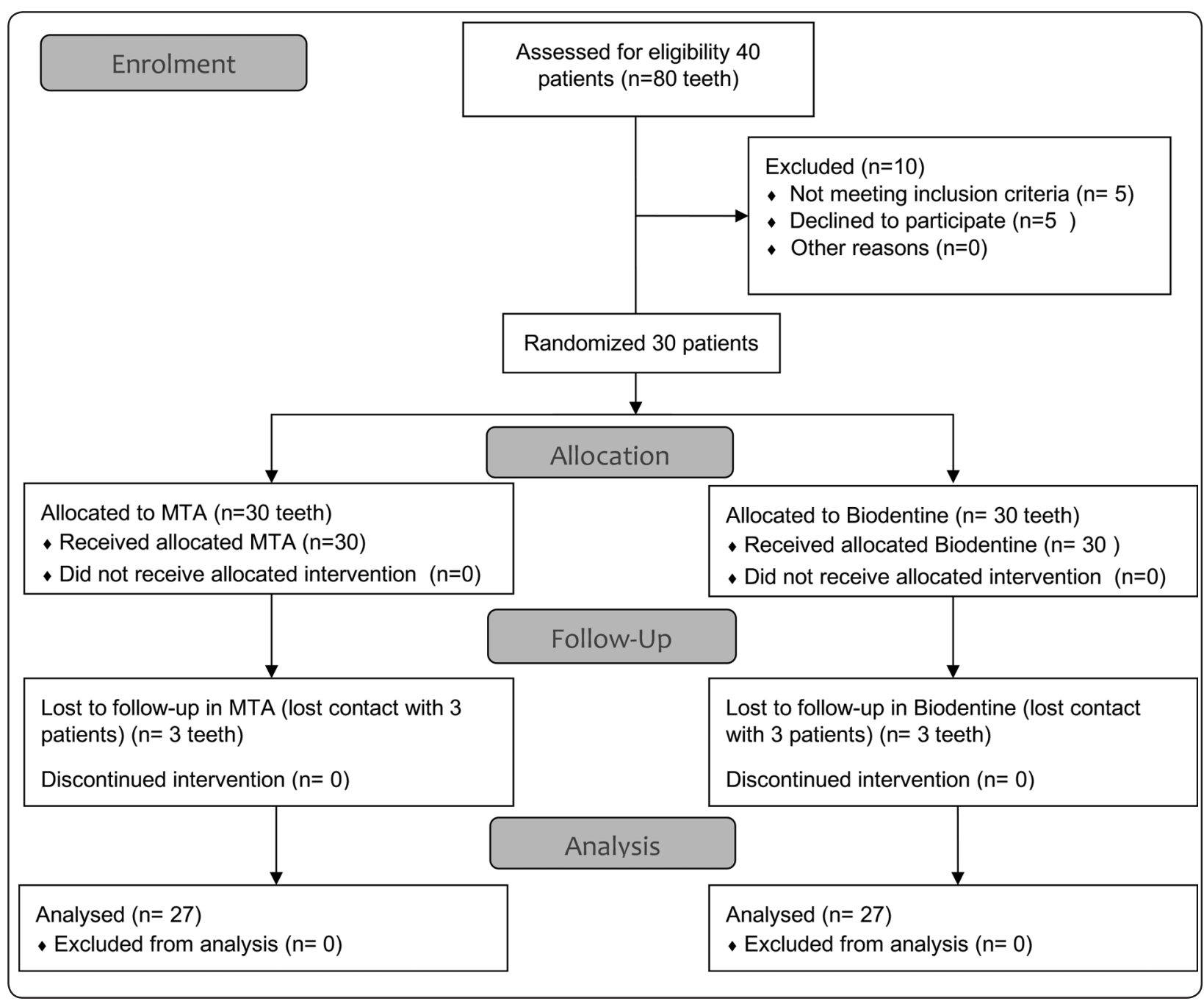

Fig. (1) A Flow diagram summarising the distribution of teeth in the two groups.

- When the progression of root formation/ development- evident radiographically- reached apical closure/ apexogenesis: score H, CR ratio $=2: 1$, apical constriction with or without signs of failure (radicular, interradicular and peri-radicular rarefaction)-, the treatment was considered complete success.

- When the progression of root formation/ development evident radiographicallycontinued to score $\mathrm{G}, \mathrm{CR}$ ratio=2: 1 , blunder buss or open apex) -with or without signs of failure (radicular, interradicular and peri-radicular rarefaction)-, the treatment was considered success.
- When the progression of root formation/ development evident radiographically failed to show any progress: score $\mathrm{F}, \mathrm{CR}$ ratio $1: 1$ or greater and funnel pulp space - with or without signs of failure (radicular, interradicular and peri-radicular rarefaction)-, the treatment was considered partial success $=$ root healing.

\section{Statistical Analysis}

Qualitative data are presented as frequencies and percentages. Since the study was a split-mouth design, Wilcoxon signed-rank test was used to compare between the two groups. Friedman's test was used to study the changes within each group. 
Kaplan-Meier survival curve was constructed to calculate the mean survival estimates of the two groups. Comparison between survival times was performed using Log rank test.

The significance level was set at $\mathrm{P} \leq 0.05$. Statistical analysis was performed with IBM ${ }^{\circledR}$ SPSS $^{\circledR}$ Statistics Version 20 for Windows. All patients were analysed according to the group to which they were randomly allocated to account for dropouts.

\section{RESULTS}

The present study was conducted on 30 patients; 13 males (43.3\%) and 17 females (56.7\%). The mean (SD) age of the patients was 7.3 (1.1) years with a range of 7.0-8.0 years.

\section{A) Clinical evaluation}

Results showing changes within the two groups from baseline and the comparison of the two groups are summarised in table (1).

\section{Pain:}

All treated teeth remained pain free in both groups at the 6-month follow-up period. However, at the last follow-up at 18 months significantly fewer $(24 / 30, p=0.002)$ teeth remained pain free in the Biodentine group and in MTA group (25/30, $\mathrm{p}=0.006$ ).

There was no statistically significant difference between presence of pain in the two groups at any of the follow-up periods

\section{Swelling}

24 teeth out of the 30 had no evidence of swelling in both groups at the 18-month followup period. Although this represented a significant decrease from baseline for both groups, there were no significant differences between the two groups at a follow-up time point. $(\mathrm{p}==0.002)$

\section{Mobility}

There was a statistically significant decrease in success rate from baseline when mobility was assessed at 18 months for both groups with number of teeth considered to be within normal limits of mobility being 24 and 25 for the Biodentine ( $\mathrm{p}=0.002)$ and MTA $(\mathrm{p}=0.002)$ group respectively. However, there was no statistically significant difference between presence of mobility when the two groups were compared at any of the follow-up intervals.

\section{Survival analysis:}

According to Kaplan-Meier survival analysis, the mean survival time for Biodentine group was 17.8 months with the $95 \%$ Confidence Interval 17.4 - 18.2 months. The mean survival time for MTA group was 18 months with 95\% Confidence Interval (18.0 - 18.0) months. There was no statistically significant difference between survival of the two groups. Figure (2)

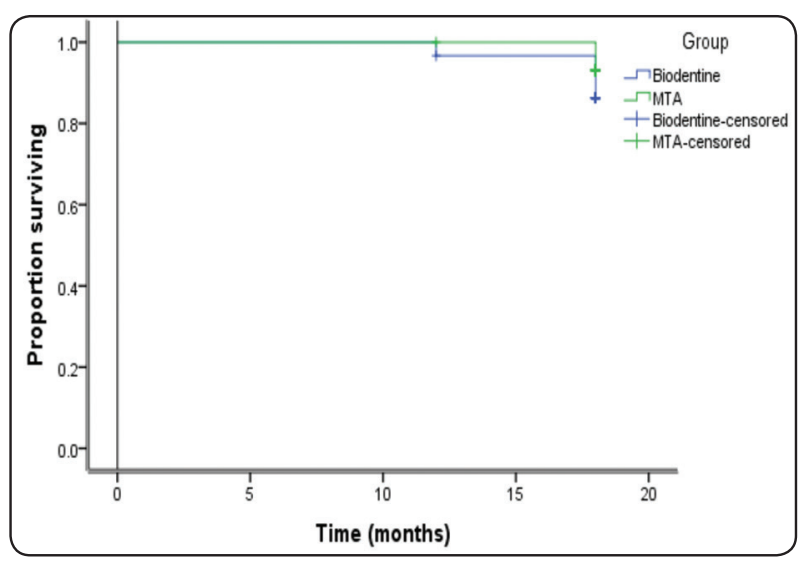

Fig. (2): Kaplan-Meier survival curve for clinical success of the two 
TABLE (1). Descriptive statistics and results of Wilcoxon signed-rank test for comparison between clinical evaluation in the two groups and Friedman's test for the changes within each group

\begin{tabular}{|c|c|c|c|c|c|c|c|}
\hline \multirow{2}{*}{ Clinical criteria } & \multirow{2}{*}{ Time } & \multicolumn{2}{|c|}{$\begin{array}{l}\text { Biodentine } \\
(\mathrm{n}=30)\end{array}$} & \multicolumn{2}{|c|}{$\begin{array}{c}\text { MTA } \\
(n=30)\end{array}$} & \multirow{2}{*}{$\begin{array}{l}P \text {-value (Between } \\
\text { groups) }\end{array}$} & \multirow{2}{*}{$\begin{array}{l}\text { Effect size } \\
\qquad(r)\end{array}$} \\
\hline & & $\mathrm{n}$ & $\%$ & $\mathrm{n}$ & $\%$ & & \\
\hline \multirow{12}{*}{ Pain } & Base line & & & & & \multirow{2}{*}{1.000} & \multirow{2}{*}{0.000} \\
\hline & Success & 30 & 100 & 30 & 100 & & \\
\hline & 6 months & \multirow{3}{*}{30} & \multirow{3}{*}{100} & \multirow{3}{*}{30} & & \multirow{2}{*}{1.000} & \multirow{2}{*}{0.000} \\
\hline & Success & & & & 100 & & \\
\hline & \multicolumn{2}{|l|}{12 months } & & & & \multirow{4}{*}{0.317} & \multirow{4}{*}{0.183} \\
\hline & Success & 28 & 93.3 & 27 & 90 & & \\
\hline & Failure & 1 & 3.3 & 2 & 6.7 & & \\
\hline & Drop-out & 1 & 3.3 & 1 & 3.3 & & \\
\hline & \multicolumn{5}{|l|}{18 months } & \multirow{4}{*}{0.564} & \multirow{4}{*}{0.105} \\
\hline & Success & 24 & 80 & 25 & 83.3 & & \\
\hline & Failure & 3 & 10 & 2 & 6.7 & & \\
\hline & Drop-out & 3 & 10 & 3 & 10 & & \\
\hline \multicolumn{2}{|c|}{$P$-value (Within group) } & \multicolumn{2}{|c|}{$0.002 *$} & \multicolumn{2}{|c|}{$0.006^{*}$} & & \\
\hline Effect s & $(w)$ & & & & & & \\
\hline & Base line & & & & & & \\
\hline & Success & 30 & 100 & 30 & 100 & 1.000 & 0.000 \\
\hline & 6 months & & & & & 1000 & 0000 \\
\hline & Success & 30 & 100 & 30 & 100 & 1.000 & 0.000 \\
\hline & 12 months & & & & & & \\
\hline Swolling & Success & 28 & 93.3 & 28 & 93.3 & & \\
\hline Swelling & Failure & 1 & 3.3 & 1 & 3.3 & 1.000 & 0.000 \\
\hline & Drop-out & 1 & 3.3 & 1 & 3.3 & & \\
\hline & 18 months & & & & & & \\
\hline & Success & 24 & 80 & 24 & 80 & & 0000 \\
\hline & Failure & 3 & 10 & 3 & 10 & 1.000 & 0.000 \\
\hline & Drop-out & 3 & 10 & 3 & 10 & & \\
\hline$P$-value (W & group) & & & & & & \\
\hline Effect s & $(w)$ & & & & & & \\
\hline & Base line & & & & & & \\
\hline & Success & 30 & 100 & 30 & 100 & 1.000 & 0.000 \\
\hline & 6 months & & & & & 1000 & 0 \\
\hline & Success & 30 & 100 & 30 & 100 & 1.000 & 0.000 \\
\hline & 12 months & & & & & & \\
\hline Mobilit & Success & 28 & 93.3 & 27 & 90 & & \\
\hline Mobility & Failure & 1 & 3.3 & 2 & 6.7 & 0.317 & 0.183 \\
\hline & Drop-out & 1 & 3.3 & 1 & 3.3 & & \\
\hline & 18 months & & & & & & \\
\hline & Success & 24 & 80 & 25 & 83.3 & 0564 & 0105 \\
\hline & Failure & 3 & 10 & 2 & 6.7 & 0.564 & 0.105 \\
\hline & Drop-out & 3 & 10 & 3 & 10 & & \\
\hline$P$-value (W & group) & & & & & & \\
\hline Effect s & $(w)$ & & & & & & \\
\hline
\end{tabular}

\footnotetext{
*: Significant at $P \leq 0.05$
} 


\section{B) Radiographic evaluation}

\section{Root formation stage:}

There was a statistically significant increase in continued root development recorded at each follow up visit in both the Biodentine $(\mathrm{p}<0.001)$, and the MTA groups $(\mathrm{P}<0.001)$, (Table 2). There were no teeth in either group at baseline with stage $\mathrm{H}$ (completed root formation) but at 18.0 months there were 20 and 21 with stage $\mathrm{H}$ root development in Biodentine and MTA groups respectively.
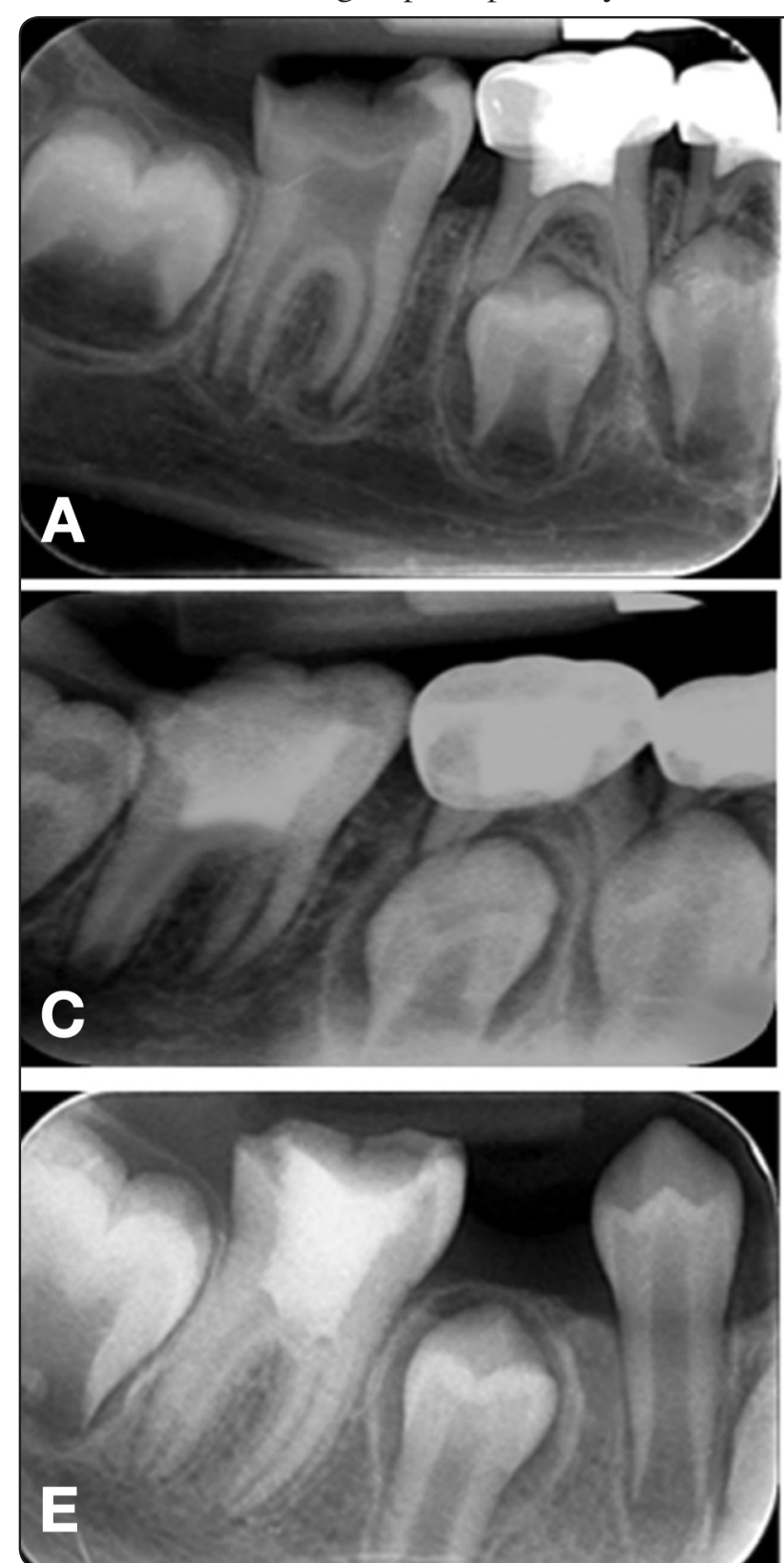

When the two groups were compared, no statistically significant difference between root formation over the follow-up periods was noted. Figures $(3,4)$ show intra-oral radiographs at the different follow-up visits of a pulpotomy performed with MTA and Biodentine as examples of various stages of root development following the treatment.

There were no statistically significant differences in the other parameters; crown: root ratios, shape of the apex or the presence of radiolucency in the two groups.
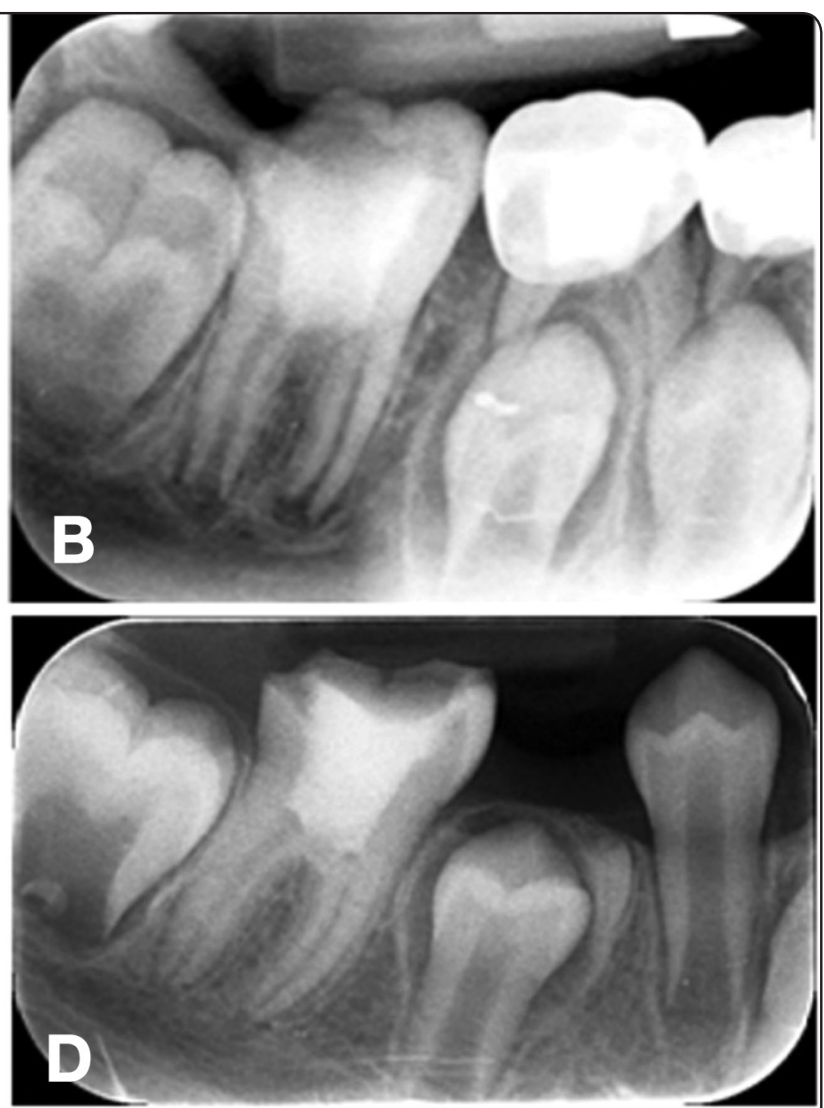

Fig. (3) (A) Intraoral digital periapical images of mandibular 1st molar preoperatively, (B) immediate postoperative restored with MTA, (C) 6 month and (D) 12 month, (E) 18 months postoperative final digital image Following the Demirjians et al, maturity scoring system for tooth development, the tooth was scored as $\mathrm{G}$ immediate postoperative, G 6 month postoperative (note the apical radiolucent area of the dental sac indicating incomplete root apex closure in C), and was scored H 12 (D) and 18 (E) months postoperative (note the uniform radiolucent outline of the periodontal membrane space around the root apically indicating complete root apex closure and complete root formation) 

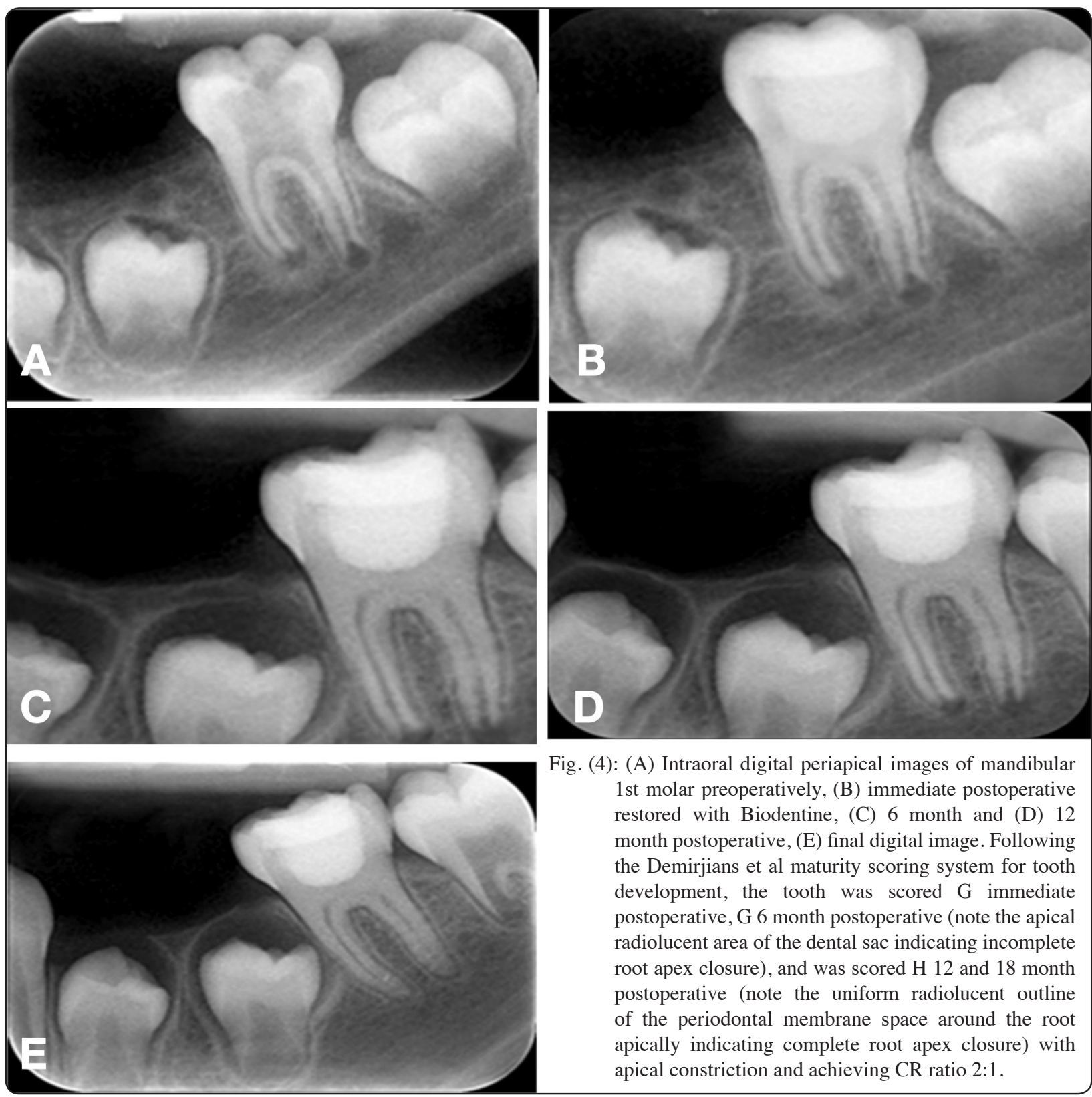

Fig. (4): (A) Intraoral digital periapical images of mandibular 1st molar preoperatively, (B) immediate postoperative restored with Biodentine, (C) 6 month and (D) 12 month postoperative, (E) final digital image. Following the Demirjians et al maturity scoring system for tooth development, the tooth was scored $\mathrm{G}$ immediate postoperative, G 6 month postoperative (note the apical radiolucent area of the dental sac indicating incomplete root apex closure), and was scored $\mathrm{H} 12$ and 18 month postoperative (note the uniform radiolucent outline of the periodontal membrane space around the root apically indicating complete root apex closure) with apical constriction and achieving CR ratio 2:1. 


\section{Radiographic success:}

There was no statistically significant difference in the overall radiographic success between the two groups, with those scored success and complete
success.(Table 2).

The overall clinical and radiographic success is summarized in Table 3

TABLE (2) Descriptive statistics and results of Wilcoxon signed-rank test for comparison between radiographic evaluation in the two groups and Friedman's test for the changes in root formation stages by time

\begin{tabular}{|c|c|c|c|c|c|c|c|}
\hline \multirow{2}{*}{$\begin{array}{l}\text { Radiographic } \\
\text { criteria }\end{array}$} & \multirow[t]{2}{*}{ Time } & \multicolumn{2}{|c|}{$\begin{array}{c}\text { Biodentine } \\
(\mathrm{n}=30)\end{array}$} & \multicolumn{2}{|c|}{$\begin{array}{c}\text { MTA } \\
(\mathrm{n}=30)\end{array}$} & \multirow{2}{*}{$\begin{array}{c}P \text {-value } \\
\text { (Between } \\
\text { groups) }\end{array}$} & \multirow{2}{*}{$\begin{array}{c}\text { Effect size } \\
(r)\end{array}$} \\
\hline & & $\mathrm{n}$ & $\%$ & $\mathrm{n}$ & $\%$ & & \\
\hline \multirow{15}{*}{$\begin{array}{l}\text { Root formation } \\
\text { stage }\end{array}$} & Base line & & & & & \multirow{3}{*}{0.157} & \multirow{3}{*}{0.258} \\
\hline & Stage $(\mathrm{F})$ & 17 & 56.7 & 19 & 63.3 & & \\
\hline & Stage (G) & 13 & 43.3 & 11 & 36.7 & & \\
\hline & \multicolumn{5}{|l|}{6 months } & \multirow{4}{*}{0.180} & \multirow{4}{*}{0.245} \\
\hline & Stage $(\mathrm{F})$ & 2 & 6.7 & 2 & 6.7 & & \\
\hline & Stage $(\mathrm{G})$ & 19 & 63.3 & 22 & 73.3 & & \\
\hline & Stage $(\mathrm{H})$ & 9 & 30 & 6 & 20 & & \\
\hline & \multicolumn{5}{|l|}{12 months } & \multirow{4}{*}{0.705} & \multirow{4}{*}{0.069} \\
\hline & Stage $(\mathrm{G})$ & 11 & 36.7 & 10 & 33.3 & & \\
\hline & Stage $(\mathrm{H})$ & 18 & 60 & 19 & 63.3 & & \\
\hline & Drop-out & 1 & 3.3 & 1 & 3.3 & & \\
\hline & \multicolumn{5}{|l|}{18 months } & \multirow{4}{*}{0.655} & \multirow{4}{*}{0.082} \\
\hline & Stage $(G)$ & 7 & 23.3 & 6 & 20 & & \\
\hline & Stage $(\mathrm{H})$ & 20 & 66.7 & 21 & 70 & & \\
\hline & Drop-out & 3 & 10 & 3 & 10 & & \\
\hline \multicolumn{2}{|c|}{$P$-value (Within group) } & \multicolumn{2}{|c|}{$<0.001 *$} & \multicolumn{2}{|c|}{$<0.001^{*}$} & & \\
\hline \multicolumn{2}{|l|}{ Effect size $(w)$} & \multicolumn{2}{|c|}{0.790} & \multicolumn{2}{|c|}{0.818} & & \\
\hline \multirow{3}{*}{ Crown : Root ratio } & $2: 1$ & 26 & 86.7 & 26 & 86.7 & \multirow{3}{*}{1.000} & \multirow{3}{*}{0.000} \\
\hline & $>2: 1$ & 1 & 3.3 & 1 & 3.3 & & \\
\hline & Drop-out & 3 & 10 & 3 & 10 & & \\
\hline \multirow{4}{*}{ Apex } & Blunder apex & 6 & 20 & 3 & 10 & \multirow{4}{*}{0.180} & \multirow{4}{*}{0.245} \\
\hline & Partially open & 1 & 3.3 & 1 & 3.3 & & \\
\hline & Constricted & 20 & 66.7 & 23 & 76.7 & & \\
\hline & Drop-out & 3 & 10 & 3 & 10 & & \\
\hline Radiolucency & & 5 & 16.7 & 4 & 13.3 & 0.705 & 0.069 \\
\hline & Success & 7 & 23.3 & 6 & 20 & & \\
\hline Success & Complete success & 20 & 66.7 & 21 & 70 & 0.564 & 0.105 \\
\hline & Drop-out & 3 & 10 & 3 & 10 & & \\
\hline
\end{tabular}


TABLE (3) Overall clinical and radiographic success through the study period

\begin{tabular}{|c|c|c|c|c|c|}
\hline \multirow[t]{2}{*}{ Success } & \multirow[t]{2}{*}{ Time } & \multicolumn{2}{|c|}{$\begin{array}{l}\text { Biodentine } \\
(\mathrm{n}=30)\end{array}$} & \multicolumn{2}{|c|}{$\begin{array}{c}\text { MTA } \\
(\mathrm{n}=30)\end{array}$} \\
\hline & & $\mathrm{n}$ & $\%$ & $\mathrm{n}$ & $\%$ \\
\hline \multirow{16}{*}{ Clinical success } & Base line & & & & \\
\hline & Success & 30 & 100 & 30 & 100 \\
\hline & Failure & 0 & 0 & 0 & 0 \\
\hline & Drop out & 0 & 0 & 0 & 0 \\
\hline & 6 months & & & & \\
\hline & Success & 30 & 100 & 30 & 100 \\
\hline & Failure & 0 & 0 & 0 & 0 \\
\hline & Drop out & 0 & 0 & 0 & 0 \\
\hline & 12 months & & & & \\
\hline & Success & 28 & 93.3 & 27 & 90 \\
\hline & Failure & 1 & 3.3 & 2 & 6.7 \\
\hline & Drop out & 1 & 3.3 & 1 & 3.3 \\
\hline & 18 months & & & & \\
\hline & Success & 24 & 80 & 24 & 80 \\
\hline & Failure & 3 & 10 & 3 & 10 \\
\hline & Drop out & 3 & 10 & 3 & 10 \\
\hline \multirow{3}{*}{ Radiographic success } & Success & 7 & 23.3 & 6 & 20 \\
\hline & Complete success & 20 & 66.7 & 21 & 70 \\
\hline & Drop-out & 3 & 10 & 3 & 10 \\
\hline
\end{tabular}

\section{DISCUSSION}

Advances in biomaterials have made possible some treatment modalities which were previously not possible. However, root canal procedures in certain clinical situations still present a real constrain, due to the root canal system complexity and the complications associated with the treatment procedures ${ }^{(16)}$. Treatment of immature permanent first molars with a compromised pulp is one of the most challenging clinical situations.

Early loss of first permanent molars can jeopardise the developing dentition, in addition to the potential traumatic experience which an extraction of a permanent molar poses for the child. From a developmental point of view loss of first permanent molars can negatively affect both arches. ${ }^{(17)}$.
The premise for vital pulp therapy is the preservation of tooth vitality, functionality and rendering the tooth asymptomatic. When a pulpotomy is performed, the part of the dental pulp presumed to be inflamed is surgically removed, and the remaining radicular dental pulp, presumed to be uninflamed and with a continued blood supply, is covered at the orifices with a biocompatible material and a coronal seal obtained which then protects the pulp from further injury and promotes healing ${ }^{(18)}$.

A pulpotomy is seldom considered for immature permanent teeth with pulp exposure, it is more universally accepted for immature permanent incisors where the exposure results from trauma rather than caries. Also, once root formation has been completed, it has been recommended that root canal therapy (RCT) be performed ${ }^{(19)}$. However, 
with newer biomaterials being introduced it is possible that the removal of the inflamed pulp and use of these materials to cover the radicular pulp tissue might provide a more long-term treatment solution, rather than one aimed purely to achieve root development followed by inevitable pulp extirpation and root canal treatment.

MTA can be used in several clinical situations, but does suffer from some limitations, such as long setting time, difficult handling and its cost, which sometimes prevents its more widespread use. Biodentine is a bioactive calcium silicate-based material with enhanced mechanical properties which claimed to overcome some of these limitations. ${ }^{(20)}$.

This randomized clinical trial used a splitmouth design, with the patients and clinicians who performed clinical/radiographic followup examinations, and the statistician all blinded to the materials used for the pulpotomy. This is essential as it is a requirement of a clinical trial, that randomization and blinding facilitate comparison between study groups and minimize bias ${ }^{(12)}$.

The difficulty of recalling patients for a clinical study such as this is acknowledged in the literature ${ }^{(21)}$. Due to the split mouth design, there were equal number of dropouts from each group with these 3 patients not returning for any further follow-ups. The statistical analysis was performed using intention to treat analysis. However, there was no attrition bias since the sample size had already been calculated with a $20 \%$ drop out factored into account for loss to follow-up.

In the present study, specified clinical and radiographic criteria were determined to evaluate the status of the pulp, and the periapical areas. This is in accordance with published literature where it has been specified that the main indicators for successful treatment are maintenance of pulp vitality, absence of postoperative sensitivity, pain or swelling and evidence of continued root development as ascertained through radiographic examination ${ }^{(22)}$.
In our study, no statistically significant differences were observed for any of the clinical or radiographic parameters when the two materials were compared. Although a statistically significant reduction in success, both clinical and radiographic, was evident within groups when compared to baseline, these results should be interpreted with caution. The overall success rate for both materials was in the region of $80 \%$ over an 18 -month period. These teeth remained functional without signs/ symptoms of pulp and periapical inflammation /infection (including spontaneous pain, sensitivity to percussion (palpation) with absence of soft tissue swelling or sinus tract and excessive mobility.

It can be difficult for clinicians to always effectively diagnose the extent of pulp contamination and inflammation. Although a history of pain, and bleeding from the amputation site, amongst other clinical indicators can give a reasonable indication whether there is inflammation present in the radicular pulp, this is not always accurate ${ }^{(23,24)}$. It is likely that the teeth in which failure was observed already had irreversible inflammation present in the radicular pulp which did not heal subsequently. Coronal leakage could be another factor that should be considered for the small number of failures observed in the two groups. However, same coronal restoration material was used in both groups this would not have been a factor for the inter-group comparison in this study.

These results are in accordance with few published studies which demonstrated that success rates decrease with time ${ }^{(25)}$. In our study teeth that were considered successful at 18 months with continued root development, and the root development completed in several teeth, as evidenced by the root maturity scores. This is an indication of pulp healing and it is not expected that these teeth will become non-vital, although there is a small possibility that pulp deterioration can occur in the long term ${ }^{(26)}$. The tooth-restoration interface, 
in contact with saliva consistently, may degrade eventually, and lead to further contamination of the pulp ${ }^{(27)}$. Clinical studies with longer follow-up periods are recommended, but all efforts must be made to restore the coronal part of the tooth with a restoration that prevents coronal leakage given the constraints of the existing restorative materials.

\section{CONCLUSIONS}

There was a high success rate for pulpotomy performed in young children in immature carious exposed permanent molars as assessed over an 18-month period, with comparable results when either MTA or Biodentine was used as a vital pulp therapy material over the amputated pulp.

\section{REFERENCES}

1. Ghoddusi J, Forghani M, Parisay I. New approaches in vital pulp therapy in permanent teeth. Iran Endod J. 2013;9(1):15-22.

2. Witherspoon DE. Vital pulp therapy with new materials: new directions and treatment perspectives--permanent teeth. Pediatr Dent. 2008;30(3):220-4.

3. Tewari RK, Mishra SK, Kumar A, Elumalai D, Kansal P, Alam S. Management Of Teeth With Open Apices ; A Narrative Review Of Etiology And Treatment Planning. American Journal of Oral Medicine and Radiology 2015;2(3):126-36.

4. Witherspoon DE, Small JC, Harris GZ. Mineral trioxide aggregate pulpotomies: a case series outcomes assessment. J Am Dent Assoc. 2006 May;137(5):610-8.

5. Akhlaghi N, Khademi A. Outcomes of vital pulp therapy in permanent teeth with different medicaments based on review of the literature. Dent Res J (Isfahan). 2015;12(5):406-17.

6. Torabinejad M, Parirokh M. Mineral trioxide aggregate: a comprehensive literature review--part II: leakage and biocompatibility investigations. J Endod. 2010 Feb;36(2):190-202.

7. Nair PNR, Duncan HF, Pitt Ford TR, Luder HU. Histological, ultrastructural and quantitative investigations on the response of healthy human pulps to experimental capping with Mineral Trioxide Aggregate: a randomized controlled trial. 2008. Int Endod J. 2009 May;42(5): 422-44.

8. Torabinejad M, Parirokh M, Dummer PMH. Mineral trioxide aggregate and other bioactive endodontic cements: an updated overview - part II: other clinical applications and complications. Int Endod J. 2018 Mar;51(3):284-317.

9. Kaur M, Singh H, Dhillon JS, Batra M, Saini M. MTA versus Biodentine: Review of Literature with a Comparative Analysis. J Clin Diagn Res. 2017 Aug;11(8):ZG01-5.

10. Alqaderi HE, Al-Mutawa SA, Qudeimat MA. MTA pulpotomy as an alternative to root canal treatment in children's permanent teeth in a dental public health setting. J Dent. 2014 Nov;42(11):1390-5.

11. Löst C. Quality guidelines for endodontic treatment: Consensus report of the European Society of Endodontology. Int Endod J. 2006;39(12):921-30.

12. Nosrat A, Seifi A, Asgary S. Pulpotomy in caries-exposed immature permanent molars using calcium-enriched mixture cement or mineral trioxide aggregate: a randomized clinical trial. Int J Paediatr Dent. 2013 Jan;23(1):56-63.

13. Kim M, Yang W, Kim H, Ko H. Comparison of the biological properties of ProRoot MTA, OrthoMTA, and endocem MTA cements. J Endod [Internet]. 2014;40(10):1649-53. Available from: http://dx.doi. org/10.1016/j.joen.2014.04.013

14. Rajasekharan S, Martens LC, Cauwels RGEC, Verbeeck RMH. Biodentine ${ }^{\mathrm{TM}}$ material characteristics and clinical applications: A review of the literature. Eur Arch Paediatr Dent. 2014;15(3):147-58.

15. Demirjian A, Goldstein H, Tanner JM. A New System Of Dental Age Assessment . Human biology, 1973: p. 211-227.

16. Solomon RV, Faizuddin U, Karunakar P, Deepthi Sarvani G, Sree Soumya S. Coronal Pulpotomy Technique Analysis as an Alternative to Pulpectomy for Preserving the Tooth Vitality, in the Context of Tissue Regeneration: A Correlated Clinical Study across 4 Adult Permanent Molars. Case Rep Dent. 2015;2015:1-12.

17. Caglaroglu M, Kilic N, Erdem A. Effects of early unilateral first molar extraction on skeletal asymmetry. Am J Orthod Dentofacial Orthop. 2008 Aug;134(2):270-5.

18. Gudkina J, Mindere A, Locane G, Brinkmane A. Review of the success of pulp exposure treatment of cariously and traumatically exposed pulps in immature permanent incisors and molars. Stomatologija. 2012;14(3):71-80. 
19. Kalaskar R, Dolas A, Kalaskar A. Apexogenesis of irreversible inflamed young permanent molar using calcium hydroxide gluconate pulpotomy: A case report with review of literature. Vol. 9, SRM Journal of Research in Dental Sciences. 2018. 141 p.

20. Camilleri J, Sorrentino F, Damidot D. Investigation of the hydration and bioactivity of radiopacified tricalcium silicate cement, Biodentine and MTA Angelus. Dent Mater. 2013 May;29(5):580-93.

21. Ward J. Vital pulp therapy in cariously exposed permanent teeth and its limitations. Aust Endod J. 2002 Apr; 28(1):29-37.

22. Cohenca N, Paranjpe A, Berg J. Vital pulp therapy. Dent Clin North Am. 2013 Jan;57(1):59-73.

23. Aguilar P, Linsuwanont P. Vital pulp therapy in vital permanent teeth with cariously exposed pulp: a systematic review. J Endod. 2011 May;37(5):581-7.

24. Ricucci D, Loghin S, Siqueira JFJ. Correlation between clinical and histologic pulp diagnoses. J Endod. 2014 Dec;40(12):1932-9.

25. Barrieshi-Nusair KM, Qudeimat MA. A prospective clinical study of mineral trioxide aggregate for partial pulpotomy in cariously exposed permanent teeth. J Endod. 2006 Aug;32(8):731-5.

26. Dammaschke T, Leidinger J, Schafer E. Long-term evaluation of direct pulp capping--treatment outcomes over an average period of 6.1 years. Clin Oral Investig. 2010 Oct;14(5):559-67.

27. Bohaty BS, Ye Q, Misra A, Sene F, Spencer P. Posterior composite restoration update: Focus on factors influencing form and function. Clin Cosmet Investig Dent. 2013; $5: 33-42$. 